\title{
Quem governa? Portugal e as novas teias da governação global
}

Who Governs? Portugal and the New Webs of Global Governance

Qui gouverne? Le Portugal et le tissu nouveau de la gouvernance globale

José Manuel Pureza

\section{CpenEdition}

\section{Journals}

Edição electrónica

URL: http://journals.openedition.org/rccs/1269

DOI: $10.4000 /$ rccs. 1269

ISSN: 2182-7435

\section{Editora}

Centro de Estudos Sociais da Universidade de Coimbra

Edição impressa

Data de publição: 1 Outubro 2002

Paginação: 99-105

ISSN: 0254-1106

Refêrencia eletrónica

José Manuel Pureza, « Quem governa? Portugal e as novas teias da governação global », Revista Crítica de Ciências Sociais [Online], 63 | 2002, colocado online no dia 01 outubro 2012, criado a 20 abril 2019. URL : http://journals.openedition.org/rccs/1269; DOI : 10.4000/rccs.1269 


\section{JOSÉ MANUEL PUREZA}

Faculdade de Economia da Universidade de Coimbra e Centro de Estudos Sociais

\section{Quem governa? Portugal e as novas teias da governação global}

O mapa da governação pós-vestefaliana está em turbulenta elaboração. A cultura institucional e regulatória moderna persiste, mas agora em combinação com processos de internacionalização da autoridade política, que desapropriam o Estado do seu monopólio nesta matéria. A "teia global" é a metáfora dessa multiplicidade de instâncias de governação global. A inserção de Portugal neste processo de transformação é ambivalente. Por um lado, dá continuidade à subalternização da sua posição mundial, o que se evidencia sobretudo no sentido de desnacionalização do Estado assumido em grande parte das reformas institucionais ocorridas recentemente no país. Mas, por outro lado, Portugal também aparece associado a sinais de novas fórmulas de governação internacional, marcadas por uma articulação militante entre Estado e não-Estado para a defesa de uma agenda transformadora das relações internacionais.

Turbulência é certamente a palavra adequada para retratar a actual cartografia institucional da globalização. Usou-a James Rosenau (1990) para caracterizar o momento que vivemos como uma bifurcação em que coexistem, de um lado, uma lógica institucional estadocêntrica, cujas expressões orgânicas se reconduzem aos rituais solenes e lentos das soberanias e, do outro, uma nova lógica institucional, a do mundo multicentrado em que se cruza um número praticamente infinito de actores cujas iniciativas tendem a ignorar totalmente a referência identitária ou regulatória aos Estados.

As narrativas da transição histórica operada nos finais do século XX deram o lastro teórico que conferiu sentido à noção de turbulência institucional. Como sabemos, foram três essas narrativas (Shaw, 2000: 2). Primeira, a da pós-modernidade, denunciadora das certezas e quietudes estabilizadas do mundo moderno, a que contrapôs a primazia da indeterminação e dos fluxos. Segunda, a narrativa do pós-Guerra Fria que, para alguns, canonizou a democracia liberal mas, para outros, foi apenas o prelúdio de uma intensa e exigente dinâmica de refrescamento da teoria e prática democráticas. Enfim, em terceiro lugar, a narrativa da globalização que, seja na sua versão hege- 
mónica, seja na sua versão contra-hegemónica, anuncia uma inédita e crescente porosidade das fronteiras - uma "política pós-internacional" (Rosenau, 1990) - deixando em aberto - e, por isso, em estado de turbulência - as recomposições institucionais exigidas por esses novos contornos.

Neste tempo de turbulência, a pergunta "quem governa?" transporta consigo a incerteza própria dos tempos de transição e a noção de que aquilo que marca o mapa institucional deste tempo é, acima de tudo, um conjunto variado e desordenado de combinações entre ruptura e continuidade com a cultura organizacional e regulatória moderna. Nas palavras de Richard Falk, estamos hoje a experimentar processos de construção e destruição institucional simétricos daqueles que ficaram simbolizados pelos tratados de 1648, celebrados na Vestefália, e que puseram fim à Guerra dos Trinta Anos:

O século XVII pôs termo a um longo movimento histórico que partiu de uma dominação não territorial centralizada e se consumou numa descentralização territorial, ao passo que o actual processo de transição parece orientado de volta a uma direcção central desterritorializada. (1989: 5)

Que cultura regulatória e institucional herdámos de Vestefália? Jon Pierre e Guy Peters (2000: 81) sintetizam esse legado em três notas principais. Em primeiro lugar, e acima de tudo, uma cultura estadocêntrica, que encara o Estado como um centro de poder absolutamente superior aos demais. A centralidade do Estado-nação no universo regulatório e institucional de Vestefália edificou-se sobre a simultaneidade da descentralização do poder em termos internacionais e da centralização do poder no interior das fronteiras dos Estados. E esta conjugação alicerçou-se em dois contrastes institucionais que estão no centro da herança vestefaliana: por um lado, o contraste entre público e privado, com o processo de afirmação hierárquica do primeiro sobre o segundo a ser coroado pelo mandamento weberiano do monopólio do uso legítimo da força; por outro lado, o contraste entre interno e externo, com o primeiro a ser representado como domínio da ordem, da paz e da relação contratual, ficção que é potenciada pela representação do externo como o campo da anarquia, da guerra de todos contra todos e da insusceptibilidade de regras vinculativas e minimamente influentes.

A segunda nota característica do modelo institucional vestefaliano, intimamente associada a esta primeira, é a da compreensão do Estado como uma entidade soberana, o que supõe uma absolutização dos seus poderes, incluindo, em última análise, o poder de definir os poderes. 
Em terceiro lugar, Pierre e Peters apontam a insularidade e a homogeneidade institucional. Na cultura institucional vestefaliana, em que governação não é outra coisa senão actividade do governo como órgão do Estado, não há lugar para parcerias entre o governo e outros actores mas sim para a efectivação impositiva das prerrogativas de jurisdição legalmente atribuídas ao poder público. Ao que acresce uma compreensão homogénea das instituições, de que a construção weberiana da burocracia é exemplar.

Ora, esta cultura institucional - em que a territorialização de base nacional e a equivalência entre governação e governo são marcas absolutamente fundamentais - tem vindo a ser sujeita a um desencontrado processo de erosão e transformação. O processo de "internacionalização da autoridade política" de que dá conta a literatura crítica de Relações Internacionais (Wendt, 1997) passou, ao longo do século XX, por uma dinâmica de "formação estatal internacional" que, de acordo com Alexander Wendt (ibid.: 57), é ainda tematicamente confinada (issue-specific) e, em grande medida, de alcance apenas regional. O processo de criação das organizações intergovernamentais de cooperação e de integração ao longo da segunda metade do século passado materializou efectivamente a estratégia de internacionalização da lógica regulatória própria do princípio do Estado, ensaiando aquilo a que já se chamou projecção mundial do Estado regulador do New Deal (Burley, 1993).

Ora, se já esta primeira importante transformação dos modos e cenários de governação implicou uma progressiva desarticulação da soberania, em que diferentes funções do Estado são desempenhadas a diferentes níveis de agregação (Shaw, 2000: 93), a viragem para o século XXI acrescentou mais turbulência e complexidade a este fenómeno central que é a emancipação da governação relativamente ao governo. Devemos a James Rosenau a definição mais conclusiva da "governação sem governo":

[G]overno significa um conjunto de actividades que são levadas a cabo por autoridades formais, pelo poder político [...], enquanto governação se refere a actividades assentes em valores partilhados, resultantes ou não de responsabilidades impostas formalmente pela lei, e que não requerem inevitavelmente o apoio do poder político para ultrapassar as resistências e garantir o seu efectivo cumprimento. (1992: 4)

A multiplicação das fórmulas institucionais e a disseminação das competências regulatórias são marcas do tempo da globalização e da governação sem governo que a caracteriza. A par do robustecimento de plataformas intergovernamentais multilaterais de tipo clássico (por exemplo, no domínio da disciplina orçamental ou no estabelecimento de parâmetros de políticas educativas), emergem fenómenos novos como as redes horizontalizadas de 
empresas de alcance global ou as alianças transnacionais de movimentos cidadãos, ou ainda parcerias temáticas entre Estados e entidades não estatais para combate por causas transformadoras do status quo internacional. Aos velhos movimentos sociais, organizados como resposta aos processos de estruturação das relações de poder económico e político no interior dos Estados, acrescem os novos movimentos sociais, cuja espacialidade de referência é a das vítimas, a da identidade sexual ou a dos ecocídios. À velha consideração de que todo o Direito é Direito do Estado contrapõe-se uma malha cada vez mais diversificada e caótica de fórmulas sub-, para-, inter- e supra-estatais de regulação e de solução dos conflitos, em que os mecanismos de auto-regulação assumem lugar de crescente importância. E, a par de tudo isto, é o próprio velho Estado vestefaliano que se reconfigura para tomar parte também no mapa institucional da globalização. Neste sentido, Alexander Wendt sublinha que o resultado destas mudanças

não é nem anarquia nem hierarquia, mas a emergência de uma nova forma de Estado e, consequentemente, de sistema interestatal, que rompe com a concidência entre Estado-como-actor e Estado-como-estrutura. Como tal, a erosão da soberania de cada Estado não implica a erosão do Estado. A soberania não é uma característica intrínseca da actuação do Estado, mas tão só uma identidade social que o Estado pode ter. Transferindo-a para outros colectivos, os Estados podem até reforçar a sua capacidade de resolver problemas. A internacionalização é um modo de reorganizar e relançar o poder do Estado - e não necessariamente um afastamento do Estado. (Wendt, 1997: 61)

Apesar desta persistência do Estado como rosto institucional no mapa da globalização, a substituição de uma leitura estadocêntrica por uma perspectiva multidimensional da governação tornou-se imperativa. A governação global, na imensa diversidade dos seus actores e das respectivas agendas políticas, configura-se como uma governação simultaneamente difusa e fragmentada, por um lado, e reconcentrada por outro.

Em si mesmo, o conceito de governação global é vazio de conteúdo político. Ilustra-o a aproximação conceptual proposta pela Comissão sobre Governação Global (presidida pelo social-democrata sueco Ingvar Carlson), segundo a qual governação constitui "a soma das muito diversas formas como os indivíduos e as instituições, públicas e privadas, gerem os seus assuntos comuns", envolvendo não apenas as relações intergovernamentais, mas "também as organizações não-governamentais, os movimentos de cidadãos, as empresas multinacionais e o mercado global de capital" (1995: 2-4). Ora, esta neutralidade política do conceito de governação glo- 
bal e a sua diferenciação relativamente ao conceito tradicional de governo não dão resposta à questão decisiva que percorre a reflexão de Gramsci: quem é o príncipe moderno? Ao sugerir que o príncipe é sempre um actor colectivo, Gramsci antecipou a bifurcação em que hoje nos encontramos quando deparamos com a pergunta "quem governa nas novas teias da governação global?” Eu creio, seguindo Martin Shaw (2000: 96), que há duas respostas para essa pergunta: por um lado, o "Estado internacionalizado", transposição para a escala transnacional do princípio vestefaliano, em relação de articulação, com uma intensidade variável, com o poder auto-regulatório das empresas e mercados globais; por outro lado, os movimentos da sociedade civil global - em que incluo quer "velhos" quer "novos" movimentos sociais - que projectam uma globalização alternativa. Mas creio igualmente que, seguindo agora a sugestão de Boaventura de Sousa Santos (1998: 42), estamos no limiar do surgimento de novos rostos institucionais da globalização, formas compósitas de Estado e não-Estado, transformado este em novíssimo movimento social de combate, articulado com ONG's transnacionais (os processos conducentes à criação do Tribunal Penal Internacional ou à adopção da Convenção de Interdição das Minas Anti-Pessoal são disso ilustrações expressivas).

A governação pós-vestefaliana está, pois, longe de ter uma identidade linear e simples. A substituição da imagem estadocêntrica pela nova imagem multidimensional, feita de redes entre Estados, organizações intergovernamentais, comunidades locais, cidades, organizações não governamentais, regiões, empresas e actores privados - a "teia global" - é, afinal, um processo com expressões muito variadas, consoante o vemos a partir do centro ou da periferia do sistema mundial.

E é precisamente aqui que radica a especificidade do caso de Portugal. A condição semiperiférica do nosso país e a circunstância decisiva de a inserção de Portugal no novo contexto global se vir operando principalmente pela via da assimilação dos esquemas institucionais e regulatórios da União Europeia determinam um novo retrato singular.

Os estudos reunidos no volume $A$ teia global. Movimentos sociais e instituições (Pureza e Ferreira, 2002) são pedaços úteis desse novo retrato turbulento que importa fazer da sociedade portuguesa. Aí se evidenciam três traços marcantes da velha/nova singularidade portuguesa.

Em primeiro lugar, o modo específico como se experimentou a centralidade do Estado no panorama institucional português ao longo das últimas décadas - e que o trabalho desenvolvido no Centro de Estudos Sociais foi captando em referências como o Estado paralelo, o Estado heterogéneo, a sociedade providência ou o Estado-como-imaginação-do-centro - tem uma 
das suas contra-faces principais na exiguidade e debilidade dos movimentos sociais. E porventura mais ainda na endémica falta de autonomia dos movimentos sociais relativamente ao Estado (de que o crescente peso do neocorporativismo em Portugal é um sinal indiscutivelmente forte). Por isso, não surpreende que a inserção dos movimentos sociais (dos consumidores à defesa do ambiente, passando pelo movimento sindical ou pelas lutas pelos novos direitos humanos) no espaço simbólico venha sendo, ela própria, vincadamente subalterna.

Em segundo lugar, Portugal é hoje atravessado por inúmeras dinâmicas de reconfiguração do espaço regulatório tradicionalmente ocupado pelo Estado. Em termos gerais, as transformações operadas no Estado legislador e no Estado regulador de conflitos vão no sentido de uma desnacionalização dos poderes de elaboração normativa e de uma descentragem dos modos de resolução dos conflitos. Em cada um destes domínios, fazem-se sentir, em simultâneo, dinâmicas de padronização das políticas públicas e dos respectivos suportes institucionais, por um lado, e, por outro, uma substituição da administração impositiva por formas negociadas, formais e informais, de governação.

Em terceiro e último lugar, descortinam-se na sociedade portuguesa sinais de novos cenários institucionais de articulação internacional militante entre Estado e não-Estado. É significativo que seja no domínio ambiental - veja-se o protagonismo assumido por Portugal no dossier oceanos - e dos direitos humanos - em especial, com o caso de Timor Leste - que se faz sentir entre nós mais impetuosamente essa inovação.

Eis, enfim, para concluir, como em Portugal se reflecte o acerto das palavras de Zygmunt Bauman:

[A] integração e a divisão, a globalização e a territorialização são processos mutuamente complementares. Mais precisamente, são as duas faces do mesmo processo: a redistribuição mundial da soberania, do poder e da liberdade de agir desencadeada [...] pelo salto radical na tecnologia da velocidade. (1999: 77)

\section{Referências Bibliográficas}

Bauman, Zygmunt (1999), Globalização: As consequências bumanas. Rio de Janeiro: Jorge Zahar Editores.

Burley, A. M. (1993), «Regulating the World: Multilateralism, International Law, and the Projection of the New Deal Regulatory State», in John Gerard Ruggie (org.), Multilateralism Matters. The Theory and Praxis of an Institutional Form. New York: Columbia UP. 
Comissão sobre Governação Global (1995), Our Global Neighbourbood. Oxford: Oxford UP.

Falk, Richard (1989), Revitalizing International Law. Ames: Iowa State University Press.

Pierre, Jon; Peters, Guy (2000), Governance, Politics and the State. London: Macmillan Press.

Pureza, José Manuel; Ferreira, António Casimiro (orgs.) (2002), A teia global. Movimentos sociais e instituições. Porto: Afrontamento

Rosenau, James (1990), Turbulence in World Politics. A Theory of Change and Continuity. Princeton: Princeton UP.

Rosenau, James (1992), Governance without Government. Governance, Order and Change in World Politics. Cambridge: Cambridge UP.

Santos, Boaventura de Sousa (1998), «Reinventar a democracia: Entre o pré-contratualismo e o pós-contratualismo», Oficina do CES, 107.

Shaw, Martin (2000), Theory of the Global State. Cambridge: Cambridge UP.

Wendt, Alexander (1997), «Identity and Change in International Politics», in Yusuf Lapid; Friedrich Kratochwil (orgs.), The Return of Culture and Identity in International Relations. London: Lynne Rienner. 